\title{
Analisis Pengaruh Atribut Kemitraan terhadap Kolaborasi dan Kinerja pada Industri Foodservice di Surabaya
}

\author{
Rani A.E., Baihaqi I., dan Bramanti G.W. \\ Departemen Manajemen Bisnis, Fakultas Bisnis dan Manajemen Teknologi, Institut Teknologi Sepuluh Nopember \\ (ITS) \\ e-mail: ibaihaqi@mb.its.ac.id
}

\begin{abstract}
Abstrak-Industri foodservice di Indonesia tumbuh semakin pesat dan diprediksi akan mengalami pertumbuhan lebih dari 20 persen pada tahun 2019. Di Surabaya, jumlah restoran untuk segmen menengah ke atas berjumlah sekitar 600 usaha dan segmen menengah ke bawahmencapai 2000 usaha pada akhir tahun 2016. Namun pada kenyataannya, pertumbuhan jumlah bisnis restoran tersebut tidak sejalan dengan laju kinerja bisnis. Merencanakan pengadaan bahan baku yang mayoritas adalah perishable goods, menjadi tantangan serius bagi bisnis foodservice, hal ini diperparah oleh harga bahan baku yang tergolong sangat fluktuatif. Menghadapi tantangan yang terjadi serta persaingan yang semakin ketat tersebut, mengharuskan setiap bisnis untuk meningkatkan keunggulan kompetitifnya agar tetap mampu bersaing, salah satunya melalui kolaborasi rantai pasok. Kolaborasi mengharuskan perusahaan untuk menjaga pasokan bahan baku di tengah fluktuasi harga. Penelitian ini bertujuan untuk menganalisis pengaruh atribut kemitraan terhadap kolaborasi rantai pasok, khususnya dengan supplier, dan dampak kolaborasi tersebut terhadap kinerja operasional bisnis foodservice di Surabaya. Dengan menggunakan data dari 65 sampel bisnis foodservice di Surabaya, penelitian ini menunjukkan bahwa koordinasi dan kepercayaan berpengaruh signifikan terhadap kolaborasi rantai pasok. Ketergantungan berpengaruh signifikan namun memiliki nilai koefisien pengaruh yang negatif. Sedangkan variabel komitmen tidak berpengaruh signifikan terhadap kolaborasi. Kolaborasi rantai pasok berpengaruh signifikan positif terhadap kinerja operasional bisnis.
\end{abstract}

Kata Kunci-Atribut Kemitraan, Industri Foodservice, Kinerja Operasional, Kolaborasi Pemasok, PLS.

\section{PENDAHULUAN}

$I^{1}$ NDUSTRI foodservice di Indonesia tumbuh semakin pesat dan menjadi semakin penting bagi masyarakat, sejalan dengan era globalisasi serta pergerakan modernisasi yang tidak dapat dihindari. Kemunculan bisnis-bisnis, baik yang sudah menjamur maupun yang termasuk bisnis baru, semakin marak. Sehingga tidak dapat dipungkiri bahwa persaingan di dalamnya menjadi semakin ketat. Selain itu, terjadi perubahan tren berkunjung ke restoran dan café yang semakin digemari oleh masyarakat dari waktu ke waktu. Hal ini turut didukung oleh riset dari situs Qraved.com, yang mencatat jumlah kunjungan masyarakat Indonesia ke restoran mencapai 380 juta kali dan menghabiskan total US\$ 1,5 miliar atau setara dengan Rp 17,1 triliun selama tahun 2013.



Gambar 1. Grafik Laju Kinerja Bisnis Restoran di Indonesia.

Sumber: Data Badan Pusat Statistik 2016.

Di Surabaya, sektor bisnis restoran merupakan salah satu sektor yang mendominasi struktur ekonomi Surabaya yakni sebesar 45,06 persen. Pertumbuhan café dan restoran di Surabaya tercatat mengalami peningkatan hingga 30 persen setiap tahunnya. Namun pada kenyataannya, pertumbuhan jumlah bisnis restoran tersebut tidak sejalan dengan laju kinerja bisnis, dimana tren laju kinerja bisnis restoran di Indonesia cenderung mengalami penurunan selama lima tahun terakhir. Laju kinerja bisnis restoran juga menunjukkan tren siklus low season pada triwulan I dan II, serta siklus peak season pada triwulan III dan IV.

Komoditas bahan baku yang dikelola bisnis foodservice mayoritas berupa perishable goods, seperti contohnya daging, sayur, dan buah. Menghadapi perubahan permintaan pada saat low dan peak season, persediaan harus direncanakan secara matang guna menghindari risiko kelebihan dan kekurangan bahan baku yang membuat bisnis kehilangan penjualan. Selain itu, fluktuasi harga bahan baku juga berdampak pada profit yang dihasilkan, bahkan tidak sedikit bisnis yang harus gulung tikar karena biaya operasional bisnis tidak sebanding dengan profit. Bisnis juga dituntut untuk menjaga stabilitas harga jual karena harga menu susah berubah dalam waktu singkat.

Menghadapi tantangan yang terjadi dan persaingan yang semakin ketat tersebut, mengharuskan setiap bisnis untuk meningkatkan keunggulan kompetitifnya agar tetap mampu bersaing, salah satunya melalui kolaborasi dengan supplier. Kolaborasi merupakan kekuatan penggerak di balik manajemen rantai pasok yang efektif [1]. Keberhasilan kolaborasi dan kemitraan dengan pemasok maupun pelanggan, 
akan mengarah pada perbaikan kinerja keseluruhan [2].

Meskipun demikian, pada kenyataannya tidak sedikit pula strategi kolaborasi tidak berhasil dijalankan karena kurangnya wawasan terkait faktor yang mempengaruhi keberhasilan kolaborasi. Dalam penelitian ini, peneliti mengkombinasikan antara penelitian Mohr \& Spekman dan Simatupang \& Sridharan. Penelitian ini menganalisis pengaruh atribut kemitraan terhadap kolaborasi rantai pasok dan kinerja operasional pada bisnis foodservice di Surabaya.

\section{TINJAUAN PUSTAKA}

\section{A. Atribut Kemitraan}

Atribut kemitraan didefinisikan sebagai seperangkat konstruk terkait dengan proses yang membantu dalam memandu aliran informasi antar mitra, mengelola kedalaman dan keluasan interaksi yang terjalin, serta memahami perubahaan yang kompleks dan dinamis antar mitra [3]. Dimensi atribut kemitraan yang digunakan mengacu pada penelitian Mohr \& Spekman meliputi komitmen, koordinasi, ketergantungan, dan kepercayaan.

\section{B. Kolaborasi Rantai Pasok}

Kolaborasi merupakan salah satu bentuk interaksi dan proses sosial yang ditujukan untuk mencapai tujuan bersama dengan saling membantu, saling memahami aktivitas masingmasing, membangun kesepakatan mengenai suatu isu atau masalah, menciptakan solusi yang sesuai, serta mengedepankan nilai-nilai bersama [4]. Konsep kolaborasi rantai pasok dikategorikan ke dalam tiga dimensi yang saling berhubungan yaitu information sharing, decision synchronization, dan incentive alignment [4].

\section{Kinerja Operasional}

Menurut Slack et al. dalam Yaqoub[5], pengukuran kinerja rantai pasok suatu perusahaan berdasarkan perspektif strategi operasi meliputi pengukuran kinerja yang berdomain sumber daya, kemampuan operasional, serta proses operasional. Mengacu pada definisi tersebut, Simatupang \& Sridharan mengusulkan tiga dimensi pengukuran kinerja operasional dalam konteks rantai pasok berdasakan perspektif strategi operasi yakni fulfillment, inventory performance, dan responsiveness.

\section{METODOLOGI PENELITIAN}

\section{A. Pengumpulan Data}

Data yang digunakan dalam penelitian ini adalah data primer yaitu data hasil penyebaran kuesioner yang dilakukan pada bisnis foodservice yang berlokasi di Surabaya. Proses penyebaran kuesioner dilakukan secara langsung kepada bisnis yang telah dipilih dari daftar APKRINDO yang sudah diacak. Selanjutnya, pihak bisnis dihubungi terkait persetujuan menjadi responden. Namun, peneliti juga mendatangi secara langsung beberapa bisnis sesuai dengan daftar dikarenakan rendahnya tingkat respon dari responden.
Dimensi pengukuran yang digunakan untuk mengukur atribut kemitraan diadaptasi dari penelitian Mohr \& Spekman. Sedangkan dimensi pengukuran yang digunakan untuk mengukur kolaborasi rantai pasok dan kinerja operasional diadaptasi dari penelitian Simatupang \& Sridharan. Skala yang digunakan dalam kuesioner menggunakan skala likert 5 poin karena merupakan skala yang umum digunakan dalam penelitian mengenai persepsi.

Penelitian ini menggunakan desain systematic random sampling dengan metode ordinal kelipatan dua. Sampel penelitian ini adalah bisnis foodservice meliputi restoran, café, bakery, dan jasa catering yang berlokasi di Surabaya dan bersedia menjadi responden. Proses pengisian kuesioner diwakili oleh pemilik, manajer, atau supervisor bisnis foodservice yang berhubungan, baik secara langsung maupun tidak langsung, dengan supplier. Proses pengumpulan data dilakukan pada bulan April hingga bulan Mei 2017 kepada 93 calon responden dan terdapat total 65 kuesioner yang kembali. Profil responden dapat dilihat di Appendix I.

Analisis pada penelitian ini terdiri dari analisis deskriptif demografi dan analisis Partial Least Squares (PLS-SEM). PLS-SEM digunakan untuk mengembangkan dan membangun hipotesis penelitian, memprediksi situasi yang kompleks, menguji hubungan prediktif antar variabel,yang diteliti serta merupakan tools yang memudahkan dalam menganalisis multivariat data[6].

\section{ANALISIS DAN PEMBAHASAN}

\section{A. Validitas dan Reliabilitas}

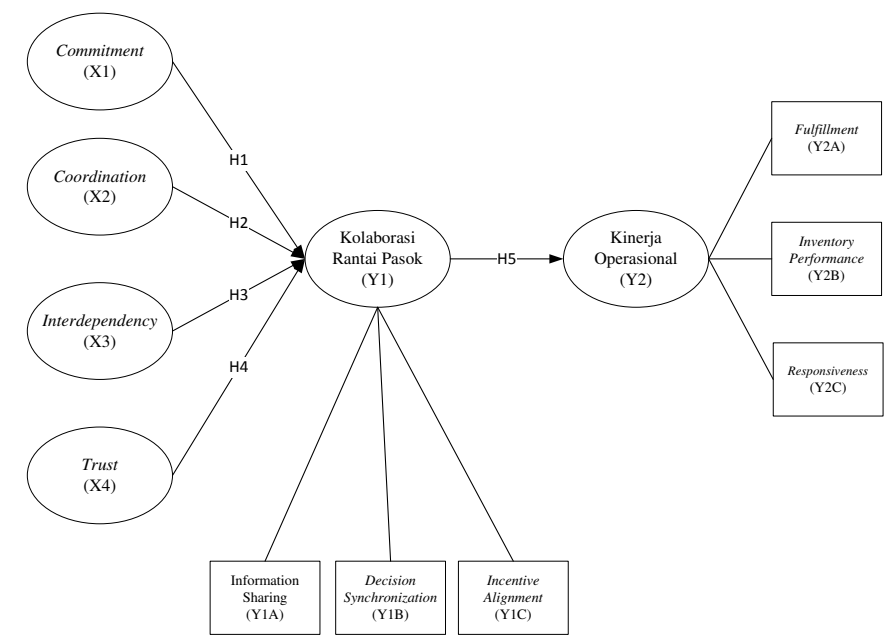

Gambar 2. Model Penelitian.

Pada PLS-SEM, uji validitas terdiri dari convergent validity, discriminant validity, dan uji reliabilitas dilihat dari nilai composite reliability. Tabel 2 menunjukkan hasil evaluasi, dimana convergent validity dikatakan telah terpenuhi apabila tiap indikator penelitian memiliki nilai outer loading lebih besar dari 0,5 serta tiap variabel memiliki nilai AVE lebih besar dari 0,5[7]. Hasil evaluasi menunjukkan bahwa seluruh indikator dan variabel telah memenuhi convergent validity. 
Discriminant validity dapat dilihat dari nilai cross loading tiap indikator serta dengan membandingkan nilai akar AVE tiap variabel terhadap korelasi antar variabel yang lainnya. Hasil menunjukkan bahwa seluruh indikator dan variabel yang digunakan dalam penelitian telah memenuhi discriminant validity. Evaluasi ketiga adalah composite reliability yang menguji nilai reliabilitas indikator-indikator pada setiap variabel penelitian. Suatu variabel dikatakan memenuhi composite reliability jika memiliki nilai lebih dari0,7. Hasil menunjukkan bahwa masing-masing variabel penelitian ini telah memenuhi kriteria composite reliability yang diharapkan.

Tabel 2.

Hasil uji validitas dan reliabilitas

\begin{tabular}{|c|c|c|c|c|}
\hline Dimensi & Indikator & $\begin{array}{c}\text { Outer } \\
\text { Loading }\end{array}$ & $\begin{array}{l}\text { Composite } \\
\text { Reliability }\end{array}$ & AVE \\
\hline \multirow{3}{*}{ Komitmen } & $\mathrm{X} 1.1$ & 0.746 & \multirow{3}{*}{0.840} & \multirow{3}{*}{0.639} \\
\hline & $\mathrm{X} 1.2$ & 0.717 & & \\
\hline & $\mathrm{X} 1.3$ & 0.920 & & \\
\hline \multirow{3}{*}{ Koordinasi } & $\mathrm{X} 2.1$ & 0.890 & \multirow{3}{*}{0.857} & \multirow{3}{*}{0.669} \\
\hline & X 2.2 & 0.722 & & \\
\hline & $\mathrm{X} 2.3$ & 0.833 & & \\
\hline \multirow{3}{*}{ Ketergantungan } & $\mathrm{X} 3.1$ & 0.915 & \multirow{3}{*}{0.913} & \multirow{3}{*}{0.779} \\
\hline & $\mathrm{X} 3.2$ & 0.907 & & \\
\hline & $\mathrm{X} 3.3$ & 0.822 & & \\
\hline \multirow{3}{*}{ Kepercayaan } & $\mathrm{X} 2.1 .1$ & 0.875 & \multirow{3}{*}{0.793} & \multirow{3}{*}{0.568} \\
\hline & $\mathrm{X} 2.1 .2$ & 0.561 & & \\
\hline & $\mathrm{X} 2.1 .3$ & 0.790 & & \\
\hline \multirow{11}{*}{$\begin{array}{c}\text { Kolaborasi } \\
\text { Rantai Pasok }\end{array}$} & Y1.A.1 & 0.649 & \multirow{4}{*}{0.864} & \multirow{4}{*}{0.616} \\
\hline & Y1.A.2 & 0.877 & & \\
\hline & Y1.A.3 & 0.778 & & \\
\hline & Y1.A.4 & 0.817 & & \\
\hline & Y1.B.1 & 0.668 & \multirow{4}{*}{0.856} & \multirow{4}{*}{0.599} \\
\hline & Y1.B.2 & 0.794 & & \\
\hline & Y1.B.3 & 0.765 & & \\
\hline & Y1.B.4 & 0.856 & & \\
\hline & Y1.C.1 & 0.819 & \multirow{3}{*}{0.885} & \multirow{3}{*}{0.720} \\
\hline & Y1.C.2 & 0.830 & & \\
\hline & Y1.C.3 & 0.895 & & \\
\hline \multirow{9}{*}{$\begin{array}{c}\text { Kinerja } \\
\text { Operasional }\end{array}$} & Y2.A.1 & 0.868 & \multirow{3}{*}{0.904} & \multirow{3}{*}{0.759} \\
\hline & Y2.A.2 & 0.899 & & \\
\hline & Y2.A.3 & 0.845 & & \\
\hline & Y2.B.1 & 0.878 & \multirow{3}{*}{0.884} & \multirow{3}{*}{0.718} \\
\hline & Y2.B.2 & 0.872 & & \\
\hline & Y2.B.3 & 0.788 & & \\
\hline & Y2.C.1 & 0.939 & \multirow{3}{*}{0.931} & \multirow{3}{*}{0.819} \\
\hline & Y2.C.2 & 0.909 & & \\
\hline & Y2.C.3 & 0.865 & & \\
\hline
\end{tabular}

\section{B. Uji Hipotesis}

Untuk menguji model struktural pada PLS-SEM, dilakukan prosedur bootstrapping. Melalui prosedur ini, dapat diperoleh nilai signifikansi koefisien jalur dan nilai $\mathrm{R}^{2}[8]$. Penilaian goodness of fit model dilihat dari nilai $\mathrm{Q}^{2}$. Penilaian goodness of fit diketahui dari nilai $\mathrm{Q}^{2}$ dapat menunjukkan kemampuan prediksi model yang dikembangkan dalam penelitian ini. Jika nilai $\mathrm{Q}^{2}$ lebih besar dari 0 , maka model dianggap memiliki relevansi prediksi yang baik. Hasil menunjukkan bahwa besarnya nilai $\mathrm{Q}^{2}$ adalah 0,707 . Hal ini menunjukkan besarnya keragaman dari data penelitian yang dapat dijelaskan oleh model struktural adalah sebesar 70,7\% sehingga dikatakan telah memiliki goodness of fit yang baik.

Selain itu, untuk memvalidasi model struktural secara keseluruhan digunakan Goodness of Fit Index (GFI), dimana penghitungannya menggunakan nilai rata-rata communalities yang diperoleh dari nilai loading factor yang dikuadratkan serta nilai rata-rata $\mathrm{R}^{2}$. Hasil penghitungan Goodness of Fit menunjukkan bahwa nilai GoF adalah sebesar 0,79 sehingga termasuk ke dalam kategori GoF besar.

Hasil menunjukkan bahwa Nilai $\mathrm{R}^{2}$ untuk variabel kolaborasi rantai pasok adalah sebesar 0,552, artinya persentase besarnya keragaman data pada variabel kolaborasi rantai pasok yang dapat dijelaskan oleh variabel komitmen, koordinasi, ketergantungandan kepercayaan adalah sebesar $55,2 \%$. Sedangkan sisanya yaitu sebesar $44,8 \%$ dijelaskan oleh faktor-faktor lain di luar penelitian ini. Variabel kinerja operasional memiliki nilai $\mathrm{R}^{2}$ sebesar 0,345 . Persentase besarnya keragaman data di variabel kinerja operasional yang dapat dijelaskan oleh variabel kolaborasi rantai pasok adalah sebesar $34,5 \%$. Dan $65,5 \%$ sisanya dijelaskan oleh faktorfaktor lain di luar penelitian ini.

Pada tahap pengujian hipotesis dilakukan dengan menggunakan $t$-test. Jika didapatkan $p$-value $\leq 0,05$ maka dapat disimpulkan bahwa hasilnya signifikan. Hipotesis penelitian dapat diterimaapabila nilai t-statistik $>\mathrm{t}$-tabel pada tingkat kesalahan $(\alpha) 5 \%$ yaitu 1,96 . Hasil uji hipotesis ditampilkan pada Tabel 3.

Tabel 3.

Hasil uji hipotesis

\begin{tabular}{lccc}
\hline \hline \multicolumn{1}{c}{ Hipotesis Penelitian } & $\begin{array}{c}\text { Koefisien } \\
\text { Jalur }\end{array}$ & T-Statistik & Hasil \\
\hline H1: Komitmen $\rightarrow$ Kolaborasi & 0.153 & 1.442 & Ditolak \\
H2: Koordinasi $\rightarrow$ Kolaborasi & 0.336 & 2.339 & Diterima \\
H3: Ketergantungan $\rightarrow$ Kolaborasi & -0.382 & 4.381 & Ditolak \\
H4: Kepercayaan $\rightarrow$ Kolaborasi & 0.213 & 2.246 & Diterima \\
H5: Kolaborasi $\rightarrow$ Kinerja OP & 0.587 & 8.860 & Diterima \\
\hline \hline
\end{tabular}

\section{KESIMPULAN}

Berdasarkan analisis deskriptif pada penelitian ini menunjukkan mayoritas responden adalah laki-laki. Dan mayoritas berusia kurang dari 30 tahun. Dari segi pendidikan terakhir, mayoritas responden merupakan lulusan sarjana. Sebagian besar dari responden menjabat sebagai pemilik bisnis dan telah menjabat lebih dari 3 tahun lamanya. Distribusi responden didominasi oleh sektor restoran yakni sebesar $31 \%$. Sedangkan untuk sektor café, bakery, dan catering memiliki proporsi yang sama yakni masing-masing sebesar $23 \%$. Mayoritas bisnis yang menjadi responden telah berdiri lebih dari 3 tahun dan mayoritas merupakan industri kecil dengan jumlah karyawan sebanyak 5-19 orang. Mayoritas bisnis telah bekerja sama dengan suppliernya lebih dari 3 tahun dan menjalin hubungan kerja sama bersifat transaksional.

Dari analisis PLS-SEM, variabel koordinasi, ketergantungan dan kepercayaan memiliki pengaruh signifikan terhadap kolaborasi. Akan tetapi, variabel ketergantungan memiliki nilai koefisien pengaruh yang negatif terhadap kolaborasi, sehingga semakin tinggi tingkat ketergantungan maka kolaborasi akan semakin menurun. Selain itu, kolaborasi juga terbukti memiliki 
pengaruh signifikan positif terhadap kinerja operasional bisnis foodservice. Penelitian ini dapat digunakan sebagai rekomendasi bagi bisnis foodservice guna meningkatkan hubungan kolaborasi dengan suppliernya. Pada penelitian ini, variabel kolaborasi hanya menjelaskan $34,5 \%$ dari kinerja operasional, sehingga penelitian selanjutnya dapat lebih mengeksplor faktor lain yang mempengaruhi kinerja.

\section{DAFTAR PUSTAKA}

[1] S. Min, P. J. Daugherty, A. S. Roath, S. E. Genchev, H. Chen, A. D. Arndt and R. G. Richey, "Supply Chain Collaboration: What's Happening?" The International Journal of Logistics Management, vol. 16, no. 2, pp. 237-256, 2005.

[2] A. Vereecke and S. Muylle, "Performance Improvement Through Supply Chain Collaboration in Europe," International Journal of Operations and Productions Management, vol. 26, no. 11, pp. 11761198, 2006.

[3] J. J. Mohr and R. E. Spekman, "Characteristics of Partnership Success: Partnership Attributes, Communication Behavior, and Conflict Resolution," Strategic Management Journal, vol. 15, no. 2, pp. 135-152, 1994.

[4] Abdulsyani, Sosiologi: Skematika, Teori dan Terapan, Jakarta: Bumi Aksara, 1994.

[5] A. M. Yaqoub, "Pengaruh Mediasi Kepercayaan Terhadap Hubungan Antara Kolaborasi Supply Chain dan Kinerja Operasi," Jurnal Manajemen dan Kewirausahaan, pp. 138-146, 2012.

[6] T. M. Simatupang and R. Sridharan, "The Collaboration Index: A Measure for Supply Chain Collaboration," International Journal of Physical Distribution and Logistics Management, vol. 35, no. 1, pp. 4462, 2005.

[7] H. Latan, Structural Equation Modeling: Konsep dan Aplikasi Menggunakan Program LISREL 8.80, Bandung: Alfabeta, 2013.

[8] J. Henseler, C. M. Ringle and R. R. Sinkovics, "The Use Of Partial Least Squares Path Modeling In International Marketing," International Marketing, vol. 20, pp. 277-319, 2009.

\section{APPENDIX}

Tabel 1.

Profil responden

\begin{tabular}{lcc}
\hline \hline \multicolumn{1}{c}{ Profil } & Frekuensi & Persentase (\%) \\
\hline Usia & 39 & \\
$\quad<30$ tahun & 16 & 60 \\
$30-40$ tahun & 10 & 25 \\
$\quad>40$ tahun & 65 & 15 \\
\hline Total & & 100 \\
\hline Jenis kelamin & 36 & \\
$\quad$ Laki-laki & 29 & 55 \\
$\quad$ Perempuan & 65 & 45 \\
\hline Total & & 100 \\
\hline Pendidikan terakhir & 7 & \\
$\quad$ Diploma & 1 & 11 \\
Lainnya & 5 & 2 \\
$\quad$ Pascasarjana & 40 & 8 \\
Sarjana & 12 & 62 \\
$\quad$ SMA atau sederajat & 65 & 18 \\
\hline Total & & \\
\hline Jala & &
\end{tabular}

Jabatan

$\begin{array}{llr}\text { Manajer } & 11 & 17\end{array}$

$\begin{array}{lll}\text { Pemilik bisnis } & 46 & 71\end{array}$

$\begin{array}{lcc}\text { Supervisor } & 8 & 12\end{array}$

\begin{tabular}{lcc}
\hline Total & 65 & 100 \\
\hline Lama bekerja & & \\
$\quad<1$ tahun & 14 & 22 \\
$2-3$ tahun & 18 & 28 \\
$>3$ tahun & 33 & 51 \\
\hline Total & 65 & 100 \\
\hline
\end{tabular}

Sektor bisnis

$\begin{array}{lll}\text { Bakery } & 15 & 23\end{array}$

Café $15 \quad 23$

$\begin{array}{lll}\text { Catering } & 15 & 23\end{array}$

Restoran $\quad 20 \quad 31$

\begin{tabular}{lcc} 
Total & 65 & 31 \\
\hline Lama becinya &
\end{tabular}

Lama berdirinya bisnis
$<1$ tahun

$2-3$ tahun $\quad 17 \quad 26$

\begin{tabular}{lcc}
\multicolumn{1}{c}{ 3 tahun } & 38 & 58 \\
\hline Total & 65 & 100 \\
\hline Jumlah karyawan & & \\
$1-4$ orang & 13 & 20 \\
$5-19$ orang & 39 & 60 \\
$>$ 20 orang & 13 & 20 \\
\hline Total & 65 & 100 \\
\hline Jenis supplier dominan & & \\
$\quad$ Supplier bahan makanan & 53 & 82 \\
$\quad$ Supplier bahan minuman & 12 & 18 \\
\hline Total & 65 & 100 \\
\hline Lama kerja sama & & \\
$\quad$ 1 tahun & 9 & 14 \\
$2-3$ tahun & 20 & 31 \\
$\quad$ 3 tahun & 36 & 55 \\
\hline Total & 65 & 100 \\
\hline Jenis kerja sama & & \\
$\quad$ Kontrak Bulanana/Tahunan & 16 & 25 \\
$\quad$ Transaksional & 49 & 75 \\
\hline Total & 65 & \\
\hline \hline
\end{tabular}

